\title{
ANÁLISE DE PROCESSOS VERBAIS EM INTRODUÇÕES DE ARTIGOS CIENTÍFICOS DE TRÊS ÁREAS: ECONOMIA, ENGENHARIA SANITÁRIA AMBIENTAL E LINGUÍSTICA SOB O VIÉS DA LINGUÍSTICA SISTÊMICO-FUNCIONAL
}

\author{
K.C.N. BRAUER ${ }^{1^{*}}$ e K.C.A. PORTELA ${ }^{2}$ \\ ${ }^{1}$ Faculdade de Tecnologia do Estado de São Paulo, ${ }^{2}$ Instituto Federal de Mato Grosso \\ kcnb@gmail.com*
}

Submetido 02/08/2016 - Aceito 29/03/2017

DOI: $10.15628 /$ holos.2017.4904

\section{RESUMO}

Este artigo investigou a distribuição e o uso dos processos em introduções de artigos científicos produzidos em três áreas: Economia, Engenharia Sanitária Ambiental e Linguística. Os aportes teóricos para o estudo das questões relacionadas às análises linguísticas foram a Gramática Sistêmico-Funcional (Halliday 1985; 1994), (Halliday \& Matthiessen, 2004). O foco da análise linguística foi na metafunção ideacional desenvolvida pela Sistêmico-Funcional. Para o levantamento de dados, foi adotada a metodologia da
Linguística de Corpus, por meio do uso do programa Wordsmith Tools 5.0 (Scott, 2009) através das ferramentas Wordlist e Concordance. $O$ estudo pretende contribuir com os profissionais e estudantes da área na compreensão dos recursos linguísticos presentes nas introduções de seus textos. Os resultados obtidos nos artigos das três áreas possibilitaram observar que os processos verbais são corresponsáveis por diferentes vozes nas construções das introduções.

PALAVRAS-CHAVE: Sistêmico- Funcional, introduções, metafunção, artigos científicos, Linguística de Corpus.

\section{VERBAL PROCESSES ANALYSIS OF SCIENTIFIC ARTICLE INTRODUCTIONS OF THREE AREAS: ECONOMIC, ENVIRONMENTAL AND SANITARY ENGINEERING AND LINGUISTICS ACCORDING TO SYSTEMIC FUNCTIONAL LINGUISTICS}

\begin{abstract}
This paper investigated the distribution and use of procedures on issues of scientific articles produced in three areas: Economic, Sanitary Environmental Engineering and Linguistics; so it analyzed the linguistic choices in issues of scientific articles. The theoretical background for the study of these issues related to linguistic analyzes contributions were the Systemic Functional Grammar (Halliday 1985, 1994), (Halliday \& Matthiessen, 2004). The focus of linguistic analysis was developed by the ideational metafunction in Systemic
\end{abstract}

Functional. For data collection methodology has been adopted in Corpus Linguistics, by using Wordsmith Tools 5.0 program (Scott, 2009) through the Concordance and Wordlist tools. This work is concerned in collaborate with professionals and students in understanding the area of language resources present in their introductions texts. The results in three areas of the articles allowed to observe that verbal processes are coresponsible in the construction of introductions and show different voices.

KEYWORDS: Systemic- functional, introductions, metafunction, scientific articles, Corpus Linguistics. 


\section{INTRODUÇÃO}

O presente trabalho apresenta uma pesquisa sobre introduções em artigos científicos das áreas de Economia, Engenharia Sanitária Ambiental e Linguística sob da perspectiva da Linguística Sistêmico-Funcional (HALLIDAY \& MATHIESSEN, 2004), que é descrita como uma abordagem que se preocupa em explorar a forma de como a língua é estruturada para o uso em diferentes contextos (EGGINGS, 1994, p. 23-24).

A investigação descrita neste artigo propõe uma análise do uso e da distribuição dos processos verbais nessas introduções com o intuito de contribuir com estudantes, profissionais a perceberem que a escrita é linguisticamente estruturada e auxiliar também no entendimento da necessidade de se preocupar com o como, o porquê e para quem se escreve a argumentação textual.

A razão da escolha do gênero desta pesquisa está associada à experiência profissional da autora do deste artigo, pois como professora de inglês e português, participou de projetos de produção textual e observou a dificuldade dos alunos frente à elaboração dos artigos científicos, principalmente, quanto à introdução. A relevância de estudar introduções está no fato de que é nesta parte do artigo que o pesquisador precisa apresentar o conhecimento e a firmeza no tratamento do assunto que segue no artigo. A introdução é a parte do artigo científico em que o autor informa o que foi pesquisado e o porquê da investigação (PEREIRA, 2011, p. 1-42). Ela é a parte do artigo que apresenta aspectos particulares da pesquisa, tais como a justificativa, a originalidade e a lógica que orientou a investigação, também objetiva mostrar que a pesquisa está assentada em bases sólidas. Assim, na introdução, se faz a ligação com a literatura, fundamentações teóricas pertinentes.

A maioria dos estudos de Introdução está preocupada com a questão da estrutura do gênero, não se voltando para a questão das escolhas linguísticas que compõem essa seção do texto. A função da introdução e o papel dos processos nessa função está em observar que a persuasão é possibilitada nesta parte do trabalho acadêmico, ou seja, na introdução. Deste modo, este trabalho objetiva uma pesquisa sobre o tema das escolhas linguísticas nas introduções, pois além do estudo de Swales (1981), há poucos sobre introduções, a não ser aqueles desenvolvidos em livros de metodologia, como dos autores Danton (2000) e Tozone-Reys (2007).

O trabalho em questão se ancora nos aportes da Linguística Sistêmico-Funcional, de Halliday $(1985,1994)$ e Halliday e Matthiessen (2004), com recursos metodológicos da Linguística de Corpus. Fundamentou-se também, nos teóricos que trabalham as questões de gêneros científicos, com ênfase nas pesquisas desenvolvidas por Bazerman $(1988,2005)$, Swales (1981, 1990, 2001), por exemplo, o trabalho sobre introduções de artigos (1981) e nas pesquisas já realizadas na área de gêneros acadêmicos (resenhas, artigos científicos) como Motta-Roth (2005, 2006) e de Paula (2009).

A metafunção ideacional ou reflexiva pela qual a linguagem organiza a experiência e a interpretação do real, em relação a tudo o que é representado foi usada neste trabalho. Conforme Halliday (1985), esta metafunção está ligada ao universo de ideias e conceitos. Nesta perspectiva, foram estudadas as três áreas Economia, Engenharia Sanitária Ambiental e Linguística e estas foram comparadas com o propósito das perguntas de pesquisa devidamente hierarquizadas, que seguem:

Quais processos verbais são mais frequentes nas introduções destas três áreas?

Como ocorre o uso destes processos verbais nas introduções dos artigos científicos? 
O autor sabe empregar corretamente os processos em introduções de artigos científicos?

Para atingir os objetivos propostos neste artigo, foram analisadas 147 introduções de artigos científicos coletados no banco de dados do LAEL, a partir de um levantamento dos processos usados na tessitura das introduções. A metodologia empregada para análise do corpus foi constituída pela utilização do programa computacional Wordsmith Tools 5.0 (Scott, 2009). Das ferramentas deste programa, foram usadas para análise Wordlist e Concordance.

Na sequência é explicitada a fundamentação teórica da pesquisa, mostrando uma visão da Linguística Sistêmico-Funcional, detendo-se na metafunção ideacional e nos teóricos sobre gêneros; também é detalhada a abordagem metodológica para tratamento do corpus; bem como apresentadas as análises realizadas; e as referências teóricas que embasaram o desenvolvimento deste artigo.

\section{REVISÃO BIBLIOGRÁFICA}

\subsection{Sob o viés da linguística sistêmico funcional}

A primeira abordagem a ser discutida neste trabalho é a Linguística Sistêmico-Funcional Halliday (1994). O modelo da sua gramática é sistêmico porque observa a gramática como um sistema de escolhas potenciais não-arbitrariamente motivadas, e é funcional porque tenta explanar as implicações comunicativas de uma seleção dentro de um desses sistemas.

De acordo com Cloran, Butte e Williams (1996, p.9), a teoria sociossemiótica da linguagem de Halliday (1994) define a ocasião do uso da linguagem em termo de contexto da situação e contexto da cultura. $O$ contexto da situação se constitui em uma maneira dinâmica na criação e na interpretação do texto, e o contexto de cultura pode ser considerado significado através da cultura, em outras palavras, de acordo com a cultura em que está inserido o participante, o texto se desenvolverá de uma maneira e trará significados específicos do mesmo.

Para Halliday (2004), na gramática sistêmico-funcional, todas as línguas organizam-se em tipos fundamentais de significado ou componentes, chamados de metafunções. São elas: a metafunção ideacional, a metafunção interpessoal e a metafunção textual. As metafunções têm um sistema que possibilita a verificação de seus significados. A metafunção ideacional ocorre pelo sistema de transitividade (que se relaciona à variável campo), a metafunção interpessoal é realizada pelo sistema de modo (que se articula à variável relação) e a metafunção textual pode ser mostrada pelo sistema temático (que se relaciona à variável modo). Portanto, como texto, neste trabalho foi usado, como macrocategoria, a metafunção ideacional.

Esta metafunção apresenta aspectos necessários para que a presente pesquisa ocorresse como: ser reflexiva, expressar processos, eventos, ações, estados ou outras características do mundo real, representadas simbolicamente. Conforme Martin e White (2005), recursos ideacionais se ocupam com a construção de experiências: o que está acontecendo, incluindo o que um faz para o outro, quando, onde, porque, como e a relação lógica de um acontecimento para o outro.

Conforme Halliday e Matthiessen (2004, p. 168-305), nesta metafunção, a oração é tida como representação, que materializa a variável campo e se relaciona a escolhas dos interlocutores que exprimem o conteúdo do texto, possibilitando, assim, ao observador tirar partido da capacidade da linguagem de representar a natureza da prática social, as experiências do mundo interior e exterior.

Segundo Halliday e Matthiessen (2004), há distinção no que é experimentado agindo no mundo exterior e no mundo da consciência, destacando a percepção, a emoção e a imaginação. A experiência exterior direciona-se aos eventos: a consciência relaciona-se às reflexões. Os 
pesquisadores afirmam que cada metafunção envolve um sistema de Transitividade ou tipo de Processo. Seus constituintes são Participantes (grupo nominal), Processos (grupo verbal) e Circunstâncias (grupos adverbiais). Processo é o elemento central na oração; os participantes estão próximos ao centro, ou seja, estão diretamente envolvidos no processo, praticando a ação ou sendo afetados por ela; os elementos circunstâncias somam informações de cunho temporal, causal, por exemplo, mas seu status é mais periférico na estrutura experiencial, pois em contrapartida aos participantes, as circunstâncias não estão diretamente envolvidas no processo. Halliday (1994) identifica em uma oração uma transitividade evidenciada por vários tipos de processos, sendo eles: material, mental, relacional, comportamental, verbal e existencial com seus significados e participantes característicos, bem como as circunstâncias que os envolvem.

Os processos materiais são processos de fazer, relacionados a ações do mundo exterior, ações realizadas no mundo físico, por exemplo, transferir, buscar. Seus participantes principais são: o Ator (quem realiza a ação propriamente dita) e a Meta (participante a quem o processo é dirigido). Segundo Thompson (1996, p.78), a presença do ator é obrigatória mesmo não sendo mencionado. Os mentais são processos de sentir (Halliday, 1994, p. 112), representam experiências em nosso mundo interior, do mundo da consciência, externando sentimentos, percepção e cognição, seus participantes são: o Experienciador (em cuja mente o processo está se realizando) e o Fenômeno (elemento sentido pelo Experienciador).

Os processos relacionais ou processos de ser representam significados ligados à identificação e à classificação. Os processos comportamentais são ações que envolvem comportamentos físicos e psicológicos realizados de forma simultânea. Eles estão na fronteira entre os materiais e os mentais, exemplos: assistir, preocupar-se. Seus participantes são: o Comportante (entidade que realiza a ação) e a Extensão (determina o escopo do processo); os processos verbais, processos de dizer, posicionam-se entre os mentais e os relacionais, trazendo relacionamentos simbólicos, construídos na consciência humana e realizados através da linguagem. Seus participantes são: o Dizente (realiza a ação), o Receptor (para quem a mensagem é direcionada), o Alvo (entidade que é atingida pelo processo) e a Verbiagem (mensagem propriamente dita). E por fim, os processos existenciais, os que se ligam a qualquer tipo de fenômeno que é reconhecido como existente, o seu participante. Exemplos: emergir, surgir e ocorrer.

Essa concepção de estudar a linguagem possibilita perceber as escolhas que o escritor fez para explicitar suas experiências no artigo produzido. Assim, surgiu o seu interesse pelo estudo de introduções em artigos científicos, pois elas aprofundam e expõem o que foi tratado no resumo e o que seguirá no artigo. Na metafunção ideacional, o conteúdo do texto possibilita ao sujeito observador tirar proveito da capacidade da linguagem de representar experiências do mundo.

\subsection{Refletindo sobre gênero}

Outras abordagens das quais esta investigação tratou são sociorretóricas fundamentadas nos trabalhos de: Swales $(1990,1993,2001)$, Bhatia (1993) e Bazerman (2005) no que se refere a gêneros. Estas abordagens contemplam a noção de gênero como ação social.

O interesse de Swales (1990) por gêneros surgiu principalmente em discursos que recaem sobre meios acadêmicos e profissionais, analisando a estruturação da linguagem. O pesquisador estudou o conceito de gênero partindo de vários enfoques, como: folclórico, literário, linguístico e retórico. Para o autor, um gênero engloba um conjunto de eventos comunicativos, dos quais os membros dividem as mesmas intenções comunicativas. Essas intenções são identificadas pelos membros especialistas da comunidade discursiva de origem e, no entanto, formam o conjunto de 
razões para o gênero. Tais razões constituem a estrutura esquemática do discurso, interferem e impõem limites à escolha de conteúdo e de estilo. (SWALES, 1990, p. 58)

Inicialmente, para Swales (1990, p. 46), os gêneros aparecem como meios comunicativos utilizados para a execução de determinados fins. Bhatia (1993, p. 43), observando essa definição, confirma essa posição, sustentando que o critério de mais relevância para identificar gênero é seu propósito comunicativo. E qualquer mudança significativa na intenção comunicativa poderá resultar em um gênero diferente, enquanto modificações menores nos auxiliam a diferenciar os subgêneros (1993, p.13).

É importante mencionar que Askehave e Swales (2001) discutem a centralidade do propósito comunicativo como única forma para a classificação de um gênero; a razão é justamente a dificuldade de identificá-lo de maneira adequada, sendo que o propósito comunicativo pode variar mesmo entre membros de uma mesma prática social. Os pesquisadores mencionam a necessidade do uso de uma abordagem metodológica para estudo dos gêneros que inclua a investigação dos contextos em que os gêneros ocorrem, considerando a identificação da comunidade, seus valores e expectativas em relação ao gênero. No entanto, Askehave e Swales (2001) ainda mencionam a relevância do propósito comunicativo para a análise do gênero desde que seja um dos critérios de pesquisa e não o único.

De acordo com Bazerman (2005, p. 22- 23), a produção de gêneros textuais é a produção de fatos sociais, acontecimentos que as pessoas creem serem verdadeiros e, desse modo, afetam a maneira como elas definem uma situação. São ações obtidas pela linguagem. A concretização dessas ações ocorre através de processos sociais típicos, recorrentes em determinadas situações, e assim, possíveis de serem compreendidas pelos membros da prática social.

Motta-Roth (2006, p.159), ao pesquisar a linguagem como gênero, observa que a ligação dialética entre texto e contexto é evidenciada de tal modo, que a interpretação do texto (linguagem) depende do entendimento das condições do contexto (sociedade) e vice-versa.

Segundo Meurer, Bonini, Motta- Roth (2005, pág. 8), o gênero, pela visão formal (como unidade de linguagem), unifica o campo e, justamente por isso, os diálogos entre várias abordagens se intensificam. Ao tomar o conceito de gênero como categoria do discurso, a Linguística Aplicada amplia o horizonte de explicações para a linguagem. Existem dois aspectos do gênero: o de unificador e o de dispersor do campo; não é fácil construir um quadro ontológico (ou mesmo didático) das correntes teóricas postas no campo.

Os aportes da Linguística Sistêmico-Funcional de Halliday e do gênero de acordo com Swales (1990, 2001), Bazerman (2005), Motta-Roth (2005) e outros contribuíram para a relevância de investigar as introduções de artigos científicos. Assim, a seguir são discutidas as questões metodológicas que orientaram esta pesquisa.

\section{METODOLOGIA}

Nesta seção, serão apresentados o corpus e os procedimentos metodológicos utilizados para o desenvolvimento e a efetivação da pesquisa.

\subsection{0 corpus}

O corpus desta pesquisa foi composto por 147 introduções de artigos científicos em língua portuguesa, assim constituído: 44 de Economia, 48 da Engenharia Sanitária Ambiental e 55 de Linguística. A fonte da qual esses artigos foram selecionados é o Scientific Eletronic Library Online (SCIELO), cujo principal objetivo é o desenvolvimento de uma metodologia comum para a preparação, armazenamento, disseminação e avaliação da produção científica em formato eletrônico. 
Para que o uso do programa Wordsmith Tools 5.0 (Scott, 2009) fosse possível, as introduções selecionadas foram armazenadas no formato Word e convertidas em formato "txt" conforme exigido pelo software. Sendo assim, cada introdução foi salva em um arquivo. Todas estas etapas são necessárias, pois a relevância deste estudo está voltada para a tessitura das introduções dos textos. Figuras, gráficos, quadros, palavras chave e referências bibliográficas, por não serem objetos de estudo, foram retirados.

\subsection{Procedimentos de análise}

Neste estudo, foi feito o levantamento bibliográfico de introduções e elementos da Gramática Sistêmico-Funcional (processos). Com o corpus das três áreas: Economia, Linguística, Engenharia Sanitária Ambiental, foram analisadas as principais características léxico-gramaticais, especificamente no que diz respeito à teoria de Halliday (1994), com a descrição e análise da língua em seu contexto, apontando o uso e a distribuição de processos nas introduções em artigos científicos.

Os textos selecionados foram descritos e analisados conforme a abordagem de Halliday (1994), e também da abordagem metodológica da Linguística de Corpus (LC). A metafunção ideacional serviu de base para entender a investigação sobre processos, pois Halliday (1994) apresenta esta metafunção considerando a oração como representação. Por meio desta, expressamos percepções do mundo, o falante e ouvinte organizam e incorporam na língua sua experiência dos fenômenos do mundo real, o que inclui sua experiência dos fenômenos do mundo interno da própria consciência (Neves,1997, p.12).

Para interpretação de dados e para responder às perguntas da pesquisa foi utilizado o Wordsmith Tool 5 (Scott, 2009). Para quantificar os usos dos processos, a ferramenta Wordlist permitiu gerar rapidamente a lista de palavras e, através do Concordance, criar listas de concordâncias de palavras para identificar a distribuição e emprego dos processos mais presentes na elaboração das introduções em artigos científicos. Segundo Berber-Sardinha (2004), a LC dedica-se ao estudo da linguagem através de evidências empíricas, extraídas com o auxílio do computador. Após observar a distribuição e o uso dos processos nas introduções de artigos científicos, foi feita uma comparação entre os processos mais recorrentes de cada uma das diferentes áreas acadêmicas (Linguística, Economia e Engenharia Sanitária Ambiental), este procedimento também foi feito com o apoio do Wordsmith Tool 5.0.

Dessa forma, a primeira parte da pesquisa envolveu o levantamento das condições de produção e a segunda parte, a análise propriamente dita dos dados. A análise de distribuição e emprego dos processos das introduções.

A estrutura linguística dos corpora foi identificada qualitativamente e quantitativamente, com base na LSF.

Por conseguinte, foi estabelecida uma comparação entre a análise da distribuição e emprego dos processos nas introduções das três áreas de artigos científicos, observando as principais características destes processos de cada domínio do saber.

A seguir a análise dos dados coletados das introduções dos artigos científicos das áreas de Linguística, Economia e Engenharia Sanitária Ambiental.

\subsection{Análise do corpus}

Como já mencionada, a análise de introduções de diferentes áreas foi feita através da eficácia do programa Wordsmith Tools 5.0 (Scott, 2009). Este programa possibilita que uma manipulação de uma grande quantidade de dados seja feita com rapidez e eficiência, mostrando os resultados que levariam até meses para serem obtidos. 
A análise foi realizada com 147 introduções de artigos científicos, 55 da área de Linguística, 43 de Economia e 48 de Engenharia Sanitária Ambiental, para observar se os dados auxiliariam a responder às questões de pesquisa bem como atingir seus objetivos.

No estudo foram analisados os processos verbais:

Quais processos verbais mais frequentes nas introduções destas três áreas?

Como ocorre o uso destes processos verbais nas introduções dos artigos científicos?

$\mathrm{O}$ autor sabe empregar corretamente os processos verbais em introduções de artigos científicos?

\section{RESULTADOS E DISCUSSÃO}

A Tabela 1 mostra os dados quantitativos do corpus. Estes dados foram retirados pelo Wordsmith Tools 5.0 (Scott, 2009) através da ferramenta Wordlist para encontrar os processos mais empregados nas introduções dos artigos científicos.

Tabela 1: Tamanho do corpus.

\begin{tabular}{c|c|c|c}
\hline Estatísticas & $\begin{array}{c}\text { Engenharia Sanitária } \\
\text { Ambiental }\end{array}$ & Economia & Linguística \\
\hline Tamanho do arquivo & 290,667 & 690,392 & 190,416 \\
Total de palavras & 44,454 & 103,937 & 29,106 \\
Palavras diferentes & 6,527 & 26,977 & 5,798 \\
Orações & 1,526 & 3,403 & 933 \\
Total de textos & 48 & 43 & 55 \\
\hline
\end{tabular}

A ferramenta de análise Wordlist foi usada para fazer as listas dos processos verbais que apareceram nas três áreas foram então separados os dez primeiros processos de cada uma das áreas. Através desta ferramenta, foi possível observar a distribuição no que diz respeito à incidência dos processos verbais nas introduções dos artigos científicos.

É relevante observar que na Tabela 1 na Linguística, tem-se um total de 55 textos com 933 orações, logo, 933 processos (mais texto e menos processo); nas outras áreas, temos menos textos e mais processos. Isso é indicativo para uma futura pesquisa, serve aqui para enriquecer o olhar de pesquisador. É certo que o tamanho dos arquivos é maior, mas há construções sintáticas envolvidas que merecem atenção quando se trata de áreas diferentes, mesmo por que se fala de gêneros acadêmicos relativamente estáveis.

$\mathrm{Na}$ Tabela 2, é possível verificar que o processo verbal mostrar é mais frequente na Economia com 73 ocorrências e está em segunda posição na Engenharia Sanitária Ambiental com 34 ocorrências, enquanto aparece em última posição na Linguística com 15 ocorrências, sendo em comum nas duas primeiras áreas.

Tabela 2: Processos verbais mais recorrentes e suas posições.

\begin{tabular}{ccccccccc}
\hline & \multirow{2}{*}{ Economia } & & \multicolumn{3}{c}{ Linguística } & \multicolumn{3}{c}{$\begin{array}{c}\text { Engenharia Sanitária } \\
\text { Ambiental }\end{array}$} \\
\hline & Processo & Freq. & & Processo & Freq. & Processo & Freq. \\
\hline 1 & Mostrar & 73 & 1 & Falar & 35 & 1 & Determinar & 51 \\
\hline 2 & Chamar & 60 & 2 & Determinar & 28 & 2 & Mostrar & 34 \\
\hline 3 & Determinar & 54 & 3 & Dizer & 26 & 3 & Chamar & 31 \\
\hline 4 & Dizer & 47 & 4 & Mostrar & 26 & 4 & Falar & 20 \\
\hline
\end{tabular}




\begin{tabular}{ccccccccc}
\hline 5 & Falar & 46 & 5 & Chamar & 26 & 5 & Estabelecer & 17 \\
\hline 6 & Estabelecer & 39 & 6 & Estabelecer & 24 & 6 & Dizer & 17 \\
\hline 7 & Sugerir & 34 & 7 & Afirmar & 22 & 7 & Destacar & 15 \\
\hline 8 & Destacar & 33 & 8 & Propor & 18 & 8 & Revelar & 12 \\
\hline 9 & Explicar & 31 & 9 & Argumentar & 16 & 9 & Demonstrar & 10 \\
\hline 10 & Demandar & 26 & 10 & Apontar & 15 & 10 & Discutir & 9 \\
\hline
\end{tabular}

O processo verbal mais recorrente na Engenharia Ambiental foi determinar, com 51 ocorrências, aparecendo igualmente em terceiro lugar nas áreas de Linguística com 26 ocorrências e Economia com 54 ocorrências, sendo o único processo comum a todas áreas. 0 processo verbal falar aparece em primeira posição na Linguística com 35 ocorrências; em sétima posição da Engenharia Sanitária Ambiental com 12 ocorrências e não aparece na Economia. O processo verbal dizer está em quarto lugar nas áreas de Economia com 47 ocorrências e na Linguística com 26 vezes e não aparece na Engenharia Sanitária Ambiental. É importante verificar que as três áreas tem em comum, em posição semelhante o processo verbal determinar com alta ocorrência.

Para fazer uma análise qualitativa dos dados, foi usada a ferramenta Concordance do software Wordsmith Tools 5.0 (Scott, 2009) a partir dessa ferramenta foi possível elaborar categorias de uso dos processos para verificar se em seus contextos realmente desempenham o papel de verbais. O processo determinar, comum as três áreas e com alta ocorrência também na análise estatística do corpus, foi apresentado como exemplo do que foi desenvolvido na análise.

$\mathrm{Na}$ ferramenta Concordance, foram feitos agrupamentos lexicais com o processo determinar através de um instrumento chamado clusters, que apresenta uma lista fixa de palavras recorrentes na concordância. Sendo feita a análise deste processo nas três áreas a partir de seus agrupamentos lexicais, foi classificado como verbal em todas elas.

A Tabela 3 mostra com frequências as formas verbais do processo "determinar".

Tabela 2: Frequência das formas verbais de "determinar".

\begin{tabular}{ccccc}
\hline $\begin{array}{c}\text { Forma Verbal e } \\
\text { número de } \\
\text { ocorrência }\end{array}$ & Economia & $\begin{array}{c}\text { Engenharia } \\
\text { Sanitária } \\
\text { Ambiental }\end{array}$ & Linguística & Total \\
\hline Determinar & 20 & 19 & 11 & 50 \\
\hline Determinada & 18 & 18 & 9 & 45 \\
\hline Determina & 10 & 11 & 4 & 25 \\
\hline Determinam & 3 & 2 & 1 & 6 \\
\hline Determinou & 2 & 1 & 1 & 4 \\
\hline
\end{tabular}

O processo determinar em alguns contextos das introduções estudadas.

a) Linguística:

[...] em seu trabalho, Richman analisou cada uma das 6500 palavras mais frequentes do espanhol, com o objetivo de determinar a porcentagem de palavras cognatas em português e estabelecer a proximidade entre o léxico dessas duas línguas [...]

b) Economia

[...] o gerente geral determinou a queda da economia para agosto [...] 
c) Engenharia Sanitária Ambiental:

[...] e o grupo determina o dia do plantio [...]

Em todos os exemplos analisados nas introduções de artigos científicos, como os acima citados, o processo determinar é verbal. Verificou-se que nas introduções aparecem mais processos verbais (processos do dizer) fazendo o papel de apresentar as vozes do texto e o que será discutido ao longo dos artigos analisados, desenvolvendo realmente o papel de uma introdução apresentar o assunto a ser tratado no artigo.

Na Tabela 4 estão apresentadas as formas do processo verbal "mostrar".

Tabela 4: Frequência das formas verbais de "mostrar".

\begin{tabular}{ccccc}
\hline $\begin{array}{c}\text { Forma Verbal e } \\
\text { número de } \\
\text { ocorrência }\end{array}$ & Economia & $\begin{array}{c}\text { Engenharia } \\
\text { Sanitária } \\
\text { Ambiental }\end{array}$ & Linguística & Total \\
\hline Mostra & 40 & 20 & 9 & 69 \\
\hline Mostrar & 20 & 10 & 3 & 33 \\
\hline Mostramos & 10 & 2 & 1 & 13 \\
\hline Mostrou & 2 & 1 & 1 & 4 \\
\hline Mostrado & 1 & 1 & 1 & 3 \\
\hline
\end{tabular}

Nessa tabela, observa-se a maior ocorrência na forma verbal da $3^{a}$ pessoa do singular nas três áreas. A alta ocorrência da 3 a pessoa do singular mostra um caráter impessoal.

A seguir, é mostrada a Tabela 5 com destaque ao verbo "chamar":

Tabela 5: Frequência das formas verbais de "chamar".

\begin{tabular}{ccccc}
\hline $\begin{array}{c}\text { Forma Verbal e } \\
\text { número de } \\
\text { ocorrência }\end{array}$ & Economia & $\begin{array}{c}\text { Engenharia } \\
\text { Sanitária } \\
\text { Ambiental }\end{array}$ & Linguística & Total \\
\hline Chamar & 40 & 20 & 9 & 69 \\
\hline Chama & 20 & 10 & 3 & 33 \\
\hline Chamamos & 10 & 2 & 1 & 13 \\
\hline Chamou & 2 & 1 & 1 & 4 \\
\hline Chamado & 1 & 1 & 1 & 3 \\
\hline
\end{tabular}

Na tabela 5, observa-se que no momento em que foi mencionado o processo chamar a forma verbal mais recorrente nas três áreas foi o infinitivo "chamar". O uso de infinitivo relaciona-se ao alto uso de modalidade (BARBARA e MACEDO, 2011).

Observa-se na tabela a seguir a frequência do processo verbal "dizer".

Tabela 6: Frequência das formas "dizer".

\begin{tabular}{ccccc}
\hline $\begin{array}{c}\text { Forma Verbal e } \\
\text { número de } \\
\text { ocorrência }\end{array}$ & Economia & $\begin{array}{c}\text { Engenharia } \\
\text { Sanitária } \\
\text { Ambiental }\end{array}$ & Linguística & Total \\
\hline Dizer & 20 & 20 & 12 & 52 \\
\hline Dizem & 12 & 10 & 10 & 32 \\
\hline
\end{tabular}




\begin{tabular}{ccccc}
\hline Disse & 11 & 2 & 2 & 15 \\
\hline Dizia & 3 & 1 & 1 & 5 \\
\hline Dizendo & 1 & 1 & 1 & 3 \\
\hline
\end{tabular}

Assim como na Tabela 5, as Tabelas 6 e 7 apresentam o maior número de ocorrências na forma no infinitivo. Mostrando um alto uso de modalidade.

$\mathrm{Na}$ Tabela 7, analisa-se mais um verbo recorrente nas introduções estudadas, o processo verbal "falar".

Tabela 7: Frequência das formas "falar".

\begin{tabular}{ccccc}
\hline $\begin{array}{c}\text { Forma Verbal e } \\
\text { número de } \\
\text { ocorrência }\end{array}$ & Economia & $\begin{array}{c}\text { Engenharia } \\
\text { Sanitária } \\
\text { Ambiental }\end{array}$ & Linguística & Total \\
\hline Falar & 21 & 10 & 11 & 42 \\
\hline Falaram & 11 & 6 & 12 & 29 \\
\hline Falam & 8 & 2 & 9 & 19 \\
\hline Falando & 5 & 1 & 2 & 8 \\
\hline Falava & 1 & 1 & 1 & 3 \\
\hline
\end{tabular}

$\mathrm{Na}$ Tabela 8 apresenta-se mais um verbo recorrente nas introduções analisadas, o processo verbal "estabelecer".

Tabela 8: Frequência das formas "falar".

\begin{tabular}{ccccc}
\hline $\begin{array}{c}\text { Forma Verbal e } \\
\text { número de } \\
\text { ocorrência }\end{array}$ & Economia & $\begin{array}{c}\text { Engenharia } \\
\text { Sanitária } \\
\text { Ambiental }\end{array}$ & Linguística & Total \\
\hline Estabelecido & 21 & 10 & 12 & 43 \\
\hline Estabeleceram & 11 & 4 & 10 & 25 \\
\hline Estabelecer & 8 & 2 & 4 & 14 \\
\hline Estabelece & 5 & 1 & 1 & 7 \\
\hline Estabelecemos & 3 & 0 & 1 & 4 \\
\hline
\end{tabular}

Analisa-se que a forma passiva aparece na Tabela 8 - estabelecido- e é relevante observarmos que a passiva é um modo do interlocutor, ao mesmo tempo, se ocultar ou se mostrar no discurso, dependendo do grau de sua aceitação dentro da academia. Segundo Swales e Feak (1999), o emprego da passiva é um recurso usado no gênero científico, tendo por objetivo evitar a identificação do agente das atividades realizadas na pesquisa e também do modo de interação com o leitor, sendo que o autor não aparece nos textos de maneira explícita.

Depois de analisar os processos verbais mais recorrentes nas introduções, empregou-se a ferramenta Concondance para identificar agrupamentos lexicais, através dos instrumentos clusters, que mostraram uma lista de sequências fixas de palavras recorrentes na concordância. A partir disso, foram encontrados padrões comuns nos 
processos verbais mais recorrentes das três áreas, entre os quais têm destaque: determinar, estabelecer, mostrar, chamar, falar, dizer.

A Tabela 9 apresenta padrões de uso com a forma verbal "determinar".

Tabela 9: Padrões de uso com "determinar".

\begin{tabular}{cccc}
\hline Padrões de uso & Economia & $\begin{array}{c}\text { Engenharia } \\
\text { Sanitária } \\
\text { Ambiental }\end{array}$ & Linguística \\
\hline Determinar que & 15 & 12 & 11 \\
\hline Pode-se determinar & 10 & 11 & 9 \\
\hline Podemos determinar & 9 & 4 & 9 \\
\hline
\end{tabular}

\section{CONSIDERAÇÕES FINAIS}

Nas introduções analisadas nas áreas de Economia, Engenharia Sanitária Ambiental e Linguística foi observada a metafunção ideacional, que expressa a experiência do mundo material ou do mundo interior (própria consciência), e tiveram destaque os processos verbais, isso quer dizer que estas três áreas apresentam as atividades linguísticas com frequência, as representações dos dizeres em suas construções textuais, os processos que estão na fronteira entre os mentais e relacionais; lembrando que o processo em comum das áreas com bastante frequência foi determinar e os dez primeiros mais frequentes nestas áreas eram todos verbais. Estas áreas apresentam em suas construções textuais processos como dizer, afirmar, mostrar, que estão vinculados a representação da fala.

Nas introduções, os processos verbais são usados como introdutores de conceitos ditos por autores que possuem autoridade no assunto abordado, isto é, essas vozes de autoridades funcionam como suportes para a análise a ser apresentada.

Ao fim deste trabalho, pode-se afirmar que os resultados demonstraram que, na escrita de introduções, os processos verbais investigados são uma ferramenta de suportes de relevante função na significação global deste gênero.

\section{REFERÊNCIAS}

Askehave, I. \& Swales, J. (2001). Genre identification and communicative purpose: a problem and a possible solution. Applied Linguistics, 22(2), 195-212.

Barbara, L. \& Macedo, M. M. (2011). Processos verbais em artigos científicos: padrões de realização da mensagem. IN: Barbara, L; Moyano, E. Textos e Linguagem acadêmica. São Paulo: Mercado de Letras.

Bhatia, V. K. (1993). Analysing genre: language use in professional settings. London: Longman. Berber-Sardinha, T. (2004). Linguística de corpus. São Paulo: Manole.

Eggins, S. (1994). An introduction to systemic functional linguistics. London: Pinter Publishers. Halliday, M. A. K. (1985). An introduction to functional grammar. London: Edward Arnold.

Halliday, M. A. K. (1994). An introduction to functional grammar. London: Edward Arnold. Second Edition.

Halliday, M. A. K. \& Matthiessen, C. M. I. M. (2004). An Introduction to Functional Grammar. 
London: Edward Arnold.

Lima-lopes, R. E. (2001). Estudos de transitividade em língua portuguesa: o perfil do gênero cartas de venda. Dissertação de Mestrado. LAEL, PUC-SP.

Meurer, J. L., Bonini, A. \& Motta-Roth, D. (2005). Gêneros: Teorias, métodos e debates. São Paulo: Parábola Editorial.

Motta-Roth, D. (2006). Escrevendo no contexto: contribuições da Linguística Sistêmico-Funcional para o ensino de redação acadêmica. PUC-SP.

Pereira, M. G. (2001). Artigos científicos: como redigir, publicar e avaliar. Rio de Janeiro: Editora Guanabara-Koogan.

Scott, M. R. (2009). WordSmith tools. Oxford: Oxford University Press.

Swales, J. M. \& Feak, C. B. (1999). Academic writing for graduate students. Michigan: The University of Michigan Press.

Swales, J. M. (1990). Genre analysis - English in academic and research settings. Cambridge: University Press.

Thompson, G. (1996). Introducing Functional Grammar. England: Ed. Arnold.

Tozone-Reys, M. F. C. (2007). Metodologia Científica. Curitiba: IESDE Brasil S.A. 